\title{
Consenso Brasileiro no Diagnóstico e Tratamento da Artrite Reumatóide
}

A artrite reumatóide (AR) é, certamente, a doença da área de reumatologia que mais sofreu avanços terapêuticos nos últimos anos. A abordagem terapêutica atual baseia-se no diagnóstico precoce, na monitoração clínica e laboratorial do processo inflamatório e na introdução de droga modificadora do curso da doença o mais rapidamente possível, para que se previna a destruição articular e a incapacidade funcional. Vários tipos de medicamentos estão disponíveis para o controle dessa doença. A atualização do consenso brasileiro no diagnóstico e tratamento da AR contou com a presença de um grupo de reumatologistas da Sociedade Brasileira de Reumatologia (SBR), que debateu sobre o diagnóstico e o tratamento atual da AR, com base em dados de extensa revisão bibliográfica, com prioridade para metaanálises, além da experiência de cada um. O texto elaborado levou em conta que o consenso deve ser aplicável em todo o território nacional, da maneira mais uniforme possível e com eqüidade social. Foram contempladas eventuais opções, permitindo ao médico reumatologista usar sensibilidade e bom senso na preservação de sua autonomia na tomada de decisões clínicas.

Manoel Barros Bértolo

Presidente da Comissão de Artrite Reumatóide da Sociedade Brasileira de Reumatologia 